\title{
Plant Defense Signaling from the Underground Primes Aboveground Defenses to Confer Enhanced Resistance in a Cost-Efficient Manner
}

\author{
Marieke Van Hulten, Jurriaan Ton, Corné M.J. Pieterse, \\ and Saskia C.M. Van Wees
}

\begin{abstract}
Plants can be induced to develop below and aboveground enhanced resistance to pathogens and herbivorous insects by root-colonizing beneficial micro-organisms. The resistance induced is broad-spectrum and can be long lasting. The enhanced resistance is based at least partially on priming of defense responses, leading to a more rapid or more intense mobilization of defense responses upon encounter with harmful organisms. Several molecular players in local and systemic tissues of plants treated with resistance-inducing microbes have been identified and are reviewed in this chapter. We also discuss the ecological consequences of expression of induced resistance through a primed defense response.
\end{abstract}

\section{Introduction}

Below the soil surface, interactions between plants and microbes take place. Plant roots are quickly colonized by members of the indigenous microflora. Colonization by pathogens could have deleterious effects on the plant, but interactions between plants and microbes can also be advantageous for both the plant and the microbe. A well-known example of symbiosis between plants and soil-borne micro-organisms is that between plants and arbuscular mycorrhizal fungi, where the fungus aids the plant in the uptake of water and mineral nutrients such as phosphate by enhancing its absorbance surface through the fungal mycelium, while the plant provides carbohydrates to the fungus (Harrison 2005). Another classical example of symbiosis is the interaction between legume plants and Rhizobium spp. bacteria, in which the bacteria induce the formation of root nodules where they fix atmospheric nitrogen to convert it into organic nitrogenous compounds that become available

M. Van Hulten, J. Ton, C.M.J. Pieterse, and S.C.M. Van Wees ( $\square)$

Faculty of Science, Plant-Microbe Interactions, Department of Biology, Utrecht University, Utrecht 3508 TB, The Netherlands

e-mail: s.vanwees@uu.nl 
for the plant, while the bacteria obtain various organic photosynthetic compounds from the plant (Spaink 2000). Plant growth-promoting rhizobacteria (PGPR) form yet another class of beneficial soil-borne micro-organisms. PGPR such as Pseudomonas spp. and Baccilus spp. colonize the rhizosphere, where they live off nutrients exuded by plant roots. They can improve plant growth either directly by augmenting photosynthesis (Zhang et al. 2008) or indirectly by suppressing plant diseases (Van Loon et al. 1998; Bloemberg and Lugtenberg 2001). Disease suppression can be established through direct effects on soil-borne pathogens, such as competition for nutrients or secretion of toxic compounds (Van Loon et al. 1998; Weller et al. 2002; De Bruijn et al. 2007). However, root colonization by PGPR was also documented to suppress diseases caused by foliar pathogens in aboveground tissue (Kloepper et al. 2004; Van Loon and Bakker 2006; Van Wees et al. 2008). This plant-mediated effect of PGPR on pathogens is dependent on activation of the host's immune response and is commonly referred to as induced systemic resistance (ISR; Van Loon 2000). In addition to PGPR, soil-borne beneficial fungi can also trigger an ISR response in plants - for instance, plant growth-promoting fungi (PGPF) that include members of Trichoderma spp. (De Meyer et al. 1998; Harman et al. 2004; Shoresh et al. 2005; Vinale et al. 2008; Segarra et al. 2009) and Piriformospora spp. (Waller et al. 2005). Moreover, mycorrhizal association has also been reported to protect systemic plant tissues (Pozo and Azcón-Aguilar 2007).

Here, the molecular mechanisms of ISR triggered by PGPR are reviewed in light of the ecological perspective of the costs and benefits that are associated with plant defense.

\section{Perception of PGPR by the Plant}

Typically, ISR is effective against a broad range of taxonomically different pathogens (Van Loon et al. 1998; Van Wees et al. 2008) and also against herbivorous insects (Zehnder et al. 2001; Van Oosten et al. 2008). ISR induction is dependent on the combination of the plant and the beneficial micro-organism. PGPR strains that induce ISR in one species may not do so in another species and vice versa, suggesting host specificity in PGPR detection. For example, Pseudomonas putida WCS358 induces ISR in Arabidopsis (Arabidopsis thaliana), but not in its closely related crop relative radish (Van Peer et al. 1991; Van Peer and Schippers 1992; Leeman et al. 1995; Van Wees et al. 1997). Conversely, Pseudomonas fluorescens WCS374 is capable of inducing ISR in radish but not in Arabidopsis (Leeman et al. 1995; Van Wees et al. 1997).

The establishment of a symbiotic interaction requires a complex dialog between the plant and the micro-organism. The plant can detect microbe-associated molecular patterns (MAMPs) of beneficial micro-organisms, such as flagellin and lipopolysaccharides (LPS), which is in analogy to the detection of pathogen-associated molecular patterns (PAMPs) of pathogenic microbes (Nürnberger et al. 2004). In support of this, purified flagellin and LPS of beneficial rhizobacteria are reported 
to elicit ISR. That bacterial mutants lacking one of these determinants are still capable of protecting plants suggests that multiple MAMPs are involved in the induction of ISR (Bakker et al. 2007). However, while PAMP detection triggers a primary defense response in plants, called PAMP-triggered immunity (PTI), which keeps nonadapted pathogens at bay (Jones and Dangl 2006; Schwessinger and Zipfel 2008), perception of beneficial microbes does not trigger such a substantial defense response (Verhagen et al. 2004; Van Wees et al. 2008), or to a much lesser extent (Liu et al. 2007), and the benefactor remains accommodated by the plant.

\section{ISR Signal Transduction}

ISR induced by several beneficial Pseudomonas strains was shown to function independent of the plant defense hormone salicylic acid (SA; Pieterse et al. 1996). This is in contrast to another well-studied form of systemically induced resistance, namely systemic acquired resistance (SAR), which is triggered upon infection by pathogens (Durrant and Dong 2004). However, the use of signaling mutants indicated that components of the signaling pathways controlled by the hormones jasmonic acid (JA) and ethylene (ET) response are required for ISR (Pieterse et al. 1998; Van Wees et al. 2008). This indicates that distinct signaling cascades underlie each form of systemically induced resistance. Concordantly, SAR is predominantly effective against biotrophic pathogens that are resisted through SA-dependent defenses, while ISR is most efficient against necrotrophic pathogens and insects (Fig. 1), which are susceptible to JA-dependent defenses. For instance, SAR was shown to protect Arabidopsis plants against turnip crinckle virus in Arabidopsis, while ISR did not (Ton et al. 2002). Conversely, ISR induced by $P$. fluorescens WCS417 was shown to be effective in Arabidopsis against the necrotrophic pathogens Alternaria brassicicola (Ton et al. 2002), Botrytis cinerea (Van der Ent et al. 2008), and Plectosphaerella cucumerina (Segarra et al. 2009), while pathogeninduced SAR was not. ISR was reported to be effective against Spodoptora exigua, a generalist herbivore on Arabidopsis; SAR could also induce resistance against this insect (Van Oosten et al. 2008). Both ISR and SAR led to protection against the biotrophic oomycete Hyaloperonospora arabidopsidis and the (hemi-)biotroph Pseudomonas syringae (Ton et al. 2002). However, this resistance was shown to be accomplished through activation of distinct signaling pathways in SAR and ISR (Cao et al. 1994; Lawton et al. 1995; Pieterse et al. 1998; Van Wees et al. 1999, 2000; Van der Ent et al. 2009b). In agreement with this, SAR and ISR have been shown to have an additive effect on the level of induced resistance against $P$. syringae (Van Wees et al. 2000). For multiple plant-benefical microbe interactions, the involvement of JA and/or ET signaling components has been reported, indicating that ISR signaling is the common route to induce systemic resistance (Van Wees et al. 2008). However, several examples of PGPR and PGPF that trigger SA-dependent SAR signaling leading to enhanced systemic resistance have been documented as well (Van Loon and Bakker 2005; Van Wees et al. 2008). 


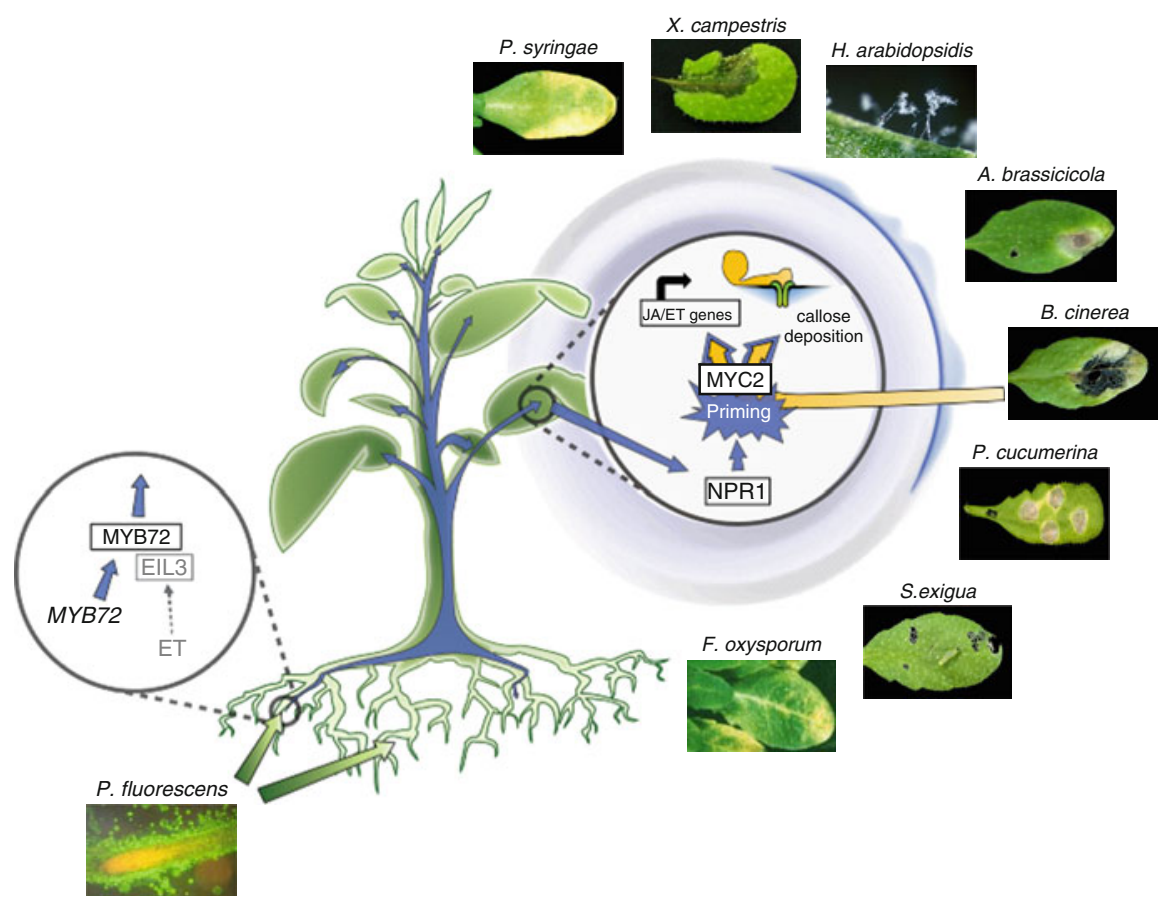

Fig. 1 Spectrum of effectiveness of Pseudomonas fluorescens WCS417-mediated ISR in Arabidopsis. ISR induced by the beneficial rhizobacterium $P$. fluorescens WCS417 is effective against the hemibiotrophic bacterial pathogens Pseudomonas syringae (Pieterse et al. 1996) and Xanthomonas campestris (Ton et al. 2002), the biotrophic oomycete Hyaloperonospora arabidopsidis (Ton et al. 2002), the necrotrophic fungal pathogens Alternaria brassicicola (Ton et al. 2002), Botrytis cinerea (Van der Ent et al. 2008) and Plectosphaerella cucumerina (Segarra et al. 2009), the fungal root pathogen Fusarium oxysporum (Van Wees et al. 1997), and the insect herbivore Spodoptora exigua (Van Oosten et al. 2008). The TF MYB72 is involved in ISR locally in the roots (formation or translocation of the ISR signal; Van der Ent et al. 2008) and the TF MYC2 is required for the priming response in systemic ISR-expressing tissue (Pozo et al. 2008). Adapted from Van Wees et al. (2008)

Microarray analysis of Arabidopsis root tissue identified a differential expression of 94 genes during rhizosphere colonization by $P$. fluorescens WCS417 (Verhagen et al. 2004). One of these genes was the R2R3-MYB-like transcription factor (TF) gene MYB72 (Verhagen et al. 2004). Interestingly, myb72 knockout mutants were incapable of mounting ISR, indicating that local MYB72 induction is required for ISR (Van der Ent et al. 2008; Fig. 1). Interestingly, in Arabidopsis, MYB72 is also essential for the induction of ISR by the beneficial fungus Trichoderma asperellum T34 (Segarra et al. 2009), suggesting a regulating role for MYB72 in the induction of ISR by taxonomically different organisms. MYB72 may be an early point of convergence in ISR signaling elicited by different MAMPs (Segarra et al. 2009). MYB72 overexpressors do not show enhanced levels of disease resistance (Van der Ent et al. 2008), indicating that although MYB72 induction is required, it is 
not sufficient for ISR induction, suggesting the involvement of an additional signal. It was demonstrated that MYB72 binds to the ETHYLENE INSENSITIVE3-LIKE (EIL3) TF in vitro, linking MYB72 function to the ET response pathway. In this respect it is noteworthy that the Arabidopsis ethylene insensitive root 1 (eirl) mutant, which is insensitive to ET in the roots but not in the shoot (Roman et al. 1995), is incapable of mounting an ISR response after root colonization by WCS417r, while leaf infiltration with WCS417r still triggered ISR in this mutant (Knoester et al. 1999). These results indicate that ISR requires an intact ET responsiveness at the site of elicitation (Knoester et al. 1999).

While most SA signaling mutants of Arabidopsis are still able to express beneficial microbe-induced ISR, the SA-nonresponsive mutant nprl (nonexpressor of PR genes 1; Cao et al. 1994; Delaney et al. 1995; Shah et al. 1997) of Arabidopsis is disturbed in WCS417-ISR (Pieterse et al. 1998). SA triggers the reduction of inactive NPR1 oligomers into active monomers, which subsequently translocate to the nucleus (Mou et al. 2003). In the nucleus NPR1 can interact with different TFs to regulate the expression of downstream genes, like $P R-1$ (Fan and Dong 2002; Wang et al. 2006). NPR1 functions in the ISR signal transduction pathway likely downstream of the JA- and ET-dependency and does not activate $P R$ gene expression (Pieterse et al. 1998). Evidence is accumulating that the role of NPR1 in ISR is connected to a cytosolic function of NPR1 (Stein et al. 2008), which is in line with a role of NPR1 in the cytosol in cross-talk between SA and JA signaling (Spoel et al. 2003; Leon-Reyes et al. 2009). Several examples of NPR1-dependency of ISR triggered by PGPR and PGPF in different plant species have been documented (Van der Ent et al. 2009a).

\section{Priming for Enhanced Defense}

Large-scale transcriptome analysis of ISR-expressing leaves in plants of which the roots were treated with WCS417 or other beneficial microbes revealed that there is no or only a weak direct induction of gene expression in systemic tissue (Verhagen et al. 2004; Liu et al. 2007; Van Wees et al. 2008). However, subsequent infection with a pathogen led to an augmented expression of a large number of genes in ISR expressing plants compared to control plants (Van Wees et al. 1999; Verhagen et al. 2004; Ahn et al. 2007; Cartieaux et al. 2008). In analogy to a similar phenomenon in animals, the enhanced defensive capacity without direct induction of defense responses in the absence of pathogens is called priming (Conrath et al. 2002, 2006). The set of genes that showed WCS417-primed induction after $P$. syringae infection of Arabidopsis was particularly enriched in JA/ET-regulated genes (Verhagen et al. 2004) that are responsive to JA/ET-inducing pathogens and insects, like $P$. syringae, A. brassicicola, Pieris rapae, and Frankliniella occidentalis (De Vos et al. 2005; Van der Ent et al. 2009a). Indeed, WCS417-ISR against the bacterial pathogen $P$. syringae and the insect Spodoptera exigua is associated with primed expression of the JA/ET-dependent genes VSP2 and 
PDF1.2, respectively (Van Wees et al. 1999; Hase et al. 2003; Pozo et al. 2008; Van Oosten et al. 2008). The specific priming of JA/ET-dependent defense responses during WCS417-mediated ISR fits with the dependency of ISR on JA/ET-dependent signaling pathways (Pieterse et al. 1998). Recently, Pozo et al. (2008) found an overrepresentation of MYC2 TF binding sites in the promoters of priming-responsive genes in ISR-expressing plants. MYC2 is a well-known player in JA-regulated signaling (Lorenzo et al. 2004). Mutant jinl which is impaired in MYC2 was incapable of mounting WCS417-ISR against $P$. syringae and $H$. arabidopsidis, indicating a central role for the MYC2 TF in WCS417-ISR (Pozo et al. 2008; Fig. 1). Also ISR induced by the beneficial fungus Piriformospora indica against Golovinomyces orontii in Arabidopsis was demonstrated to depend on MYC2 (Stein et al. 2008), supporting a role for MYC2 as an important regulator of priming during ISR induced by different microbes.

Besides priming of certain JA/ET-dependent responses, WCS417 also primes the plant to reinforce the cell wall at the site of pathogen attack. An enhanced deposition of callose-rich papillae is observed upon infection by the oomycete H. arabidopsidis in WCS417-pretreated plants (Van der Ent et al. 2008). In addition to forming a physical barrier for pathogen penetration, callose depositions are also considered to be a matrix for the accumulation of defense compounds such as $\mathrm{H}_{2} \mathrm{O}_{2}$, phenolics, and various proteins and glycoproteins with hydrolytic and antifungal properties (Zeyen et al. 2002). Priming for enhanced deposition of callose-containing papillae during WCS417-ISR in Arabidopsis is dependent on the ISR regulators MYB72, NPR1, and MYC2 (Pozo et al. 2008; Van der Ent et al. 2008, 2009b). Moreover, this ISR response is dependent on the phosphoinositide (PtdIns)- and abscisic acid (ABA)-dependent signaling components IBS2 and IBS3 (Van der Ent et al. 2009b), which were previously identified to be required for primed callose deposition induced by the priming agent $\beta$-aminobutyric acid (BABA; Zimmerli et al. 2001; Van der Ent et al. 2009b).

Priming of defense responses is also characteristic of other induced resistance phenomena. For instance, mycorrhizal fungi can prime plants for enhanced JA-regulated defense activation (Pozo and Azcón-Aguilar 2007). Insect herbivory can prime plants for a faster and stronger defense response to subsequent stresses in both systemic tissue (De Vos et al. 2006) and in neighboring plants by means of the production of volatile organic compounds (Engelberth et al. 2004; Ton et al. 2007). Although pathogen-induced SAR is accompanied by a large-scale transcriptional reprogramming of the cell (Maleck et al. 2000) and direct accumulation of PR proteins (Van Loon 1997), priming of certain defense responses also occurs during SAR (Cameron et al. 1999; Van Wees et al. 1999). While some PR proteins are thought to contribute to resistance because several of them possess antimicrobial activity (Van Loon and Van Strien 1999; Van Loon et al. 2006), direct activation of these $P R$ genes alone seems not sufficient to explain the broad range of protection (Van Loon 1997). The fact that priming can be induced in various ways and has been observed in different plant species ranging from monocots to dicots, conferring protection against a wide variety of pathogens, insects, and abiotic stresses (Conrath et al. 2006) suggests that priming appears to be a common feature of the plant's immune system. 


\section{Mechanisms of Priming of Defense Responses}

Although plants do not possess an adaptive immune system, priming may be considered as a form of immunological memory in plants. The molecular mechanisms underlying priming are the subject of research by us and other scientists. Since defense genes are not activated directly in primed plants, it was hypothesized that the primed state is based on accumulation or posttranslational modification of signal molecules that remain inactive until a subsequent stress stimulus is perceived (Conrath et al. 2006). Due to the enhanced level of signaling components, subsequent pathogen attack would lead to an increased activation of the appropriate defense pathway and thus to a potentiated activation of defense-related genes. TFs are plausible candidates to contribute to the onset of priming. Using reverse transcription quantitative polymerase chain reaction (RTq-PCR) technology, Van der Ent et al. (2009b) recently analyzed the expression of all putative Arabidopis TF genes during WCS417-ISR. The expression of 121 different types of TF genes was induced or repressed, including induction of the $M Y C 2$ gene, which had previously been identified as a player in priming during ISR (Pozo et al. 2008). Interestingly, the AP2/ERF (APETALA2/ETHYLENE-RESPONSIVE FACTORS) TF family was notably overrepresented among the upregulated TFs in ISR-expressing plants. MYC2 and several AP2/ERF TFs are implicated in the regulation of JA/ETdependent defenses (Lorenzo and Solano 2005; Pré et al. 2008).

Also priming induced by the nonprotein amino acid BABA is accompanied by direct upregulation of TF genes (Van der Ent et al. 2009b). However, while several TFs that had previously been implied in regulation of JA/ET-dependent signal transduction pathways were upregulated during ISR, pretreatment with BABA induced the expression of 22 out of the 72 known WRKY genes in the Arabidopsis genome (Van der Ent et al. 2009b). WRKY TF genes have previously been implicated in the regulation of several SA-dependent defense-related genes (Dong et al. 2003). The BABA-responsiveness of a subset of the SA-regulated WRKYs is in agreement with BABA-induced priming of SA-dependent defenses (Zimmerli et al. 2000). WCS417- and BABA-induced priming is associated with induced expression of divergent sets of TF genes, which are in accordance with the defense responses that are primed by these inducers. However, the exact role of the primingrelated TFs in the regulation of priming remains to be elucidated. Transcriptome analyses of pathogen-induced SAR expressing tissue demonstrated that TF genes are induced (Maleck et al. 2000; Wang et al. 2006), but it is unknown whether this is related to priming or to direct induction of defense responses.

There is no significant activation of defense-related genes during priming induced by treatment with WCS417 or BABA, which suggests that the accumulating TFs remain inactive until the perception of a subsequent stress signal. One way to activate TFs posttranslationally is via phosphorylation. For instance, phosphorylation of a bZIP TF is crucial for abscicic acid (ABA)-induced transcriptional activity (Kagaya et al. 2002). Interestingly, mitogen activated protein kinases (MPKs), which can phosphorylate proteins, were also recently shown to be primed 
by low concentrations of the SA analog benzothiadiazole (BTH; Beckers et al. 2009). Inactive MPK3 and MPK6 proteins accumulated in response to BTH and only subsequent exposure to pathogens led to activation of these primed MPKs (Beckers et al. 2009). Epigenetic regulation forms another possible mechanism for the priming phenomenon (Bruce et al. 2007). An altered methylation status or modification of nucleosomal histones could ensure a more accessible chromatin structure for activation of TF genes or defense-related genes, which could facilitate a quicker or more potent transcriptional response to subsequent pathogen attack. The SA-dependent SAR response is documented to be associated with epigenetic regulation as well (Mosher et al. 2006). Recently, Jung et al. (2009) discovered that the metabolite azeleic acid seems an important signal molecule in the establishment of pathogen-induced SAR. Azeleic acid is translocated in the vascular sap from local pathogen-infected tissue to systemic tissue. Application of azeleic acid confers enhanced disease resistance in Arabidopsis which is associated with priming for enhanced accumulation of SA upon pathogen challenge (Jung et al. 2009).

\section{Costs of Induced Defenses}

While some defense compounds are constitutively present such as toxic compounds that form a pre-existing chemical barrier against pathogens (Osbourn 1996), others are expressed only upon attack by a pathogen or herbivore. The inducible responses can be subjected to priming. Two prominent hypotheses have been proposed to explain the spatial and temporal variation in plant defense. These are the optimal defense theory (ODT), which predicts that plant parts with high fitness value will be highly defended, and the growth-differentiation balance hypothesis (GDBH), which assumes that a balance must be maintained between resources used for growth and defense (Barto and Cipollini 2005). It is assumed that inducible defenses are too costly to be expressed constitutively under enemy free conditions. In agreement with this, the constitutive SA-dependent defense expressing Arabidopsis mutant cprl (constitutive expressor of PR genes 1) is severely compromised in growth and seed production compared to wild-type plants (Bowling et al. 1994; Heidel et al. 2004; Van Hulten et al. 2006). This indicates a severe fitness penalty for the constitutive expression of SA-inducible defenses, which may explain why SA-dependent defenses are not expressed constitutively (Bowling et al. 1994; Heidel et al. 2004). In agreement with this, Heidel et al. (2004) observed that cprl also displays a decreased fitness under field conditions, in spite of its enhanced resistance. Interestingly, in the same field experiment, SA-insensitive nprl mutants that are defected in plant defense exhibited a decreased fitness as well, suggesting that there is a delicate balance between the costs and the benefits of inducible plant defense. Mutants that constitutively express JA- and ET-dependent defenses, such as cevl (constitutive expression of VSPI), also exhibit undersized measures (Ellis and Turner 2001). Moreover, several studies have demonstrated a fitness reduction upon direct induction of defenses by exogenous application of SA or (Me)JA 
(Baldwin 1998; Agrawal et al. 1999; Heil et al. 2000; Van Dam and Baldwin 2001; Cipollini 2002; Heidel et al. 2004).

Fitness costs can arise from various processes (Heil 2002; Heil and Baldwin 2002; Walters and Heil 2007). Allocation costs occur when limited resources are allocated to resistance traits and not to growth and reproduction. In agreement with this, several studies have reported that photosynthesis is repressed during pathogen infection, presumably to free resources needed for defense (Berger et al. 2007). One can predict that plants experience more costs of defense-related traits under lownutrient conditions. Conversely, resistance levels may be impaired due to limiting resources. Both predictions have been empirically confirmed (Cipollini 2002; Dietrich et al. 2004, 2005).

Ecological costs occur when defense expression affects other organisms besides the challenging pathogen. Activation of certain defenses may for instance have a negative effect on interactions with plant-beneficial organisms, such as mycorrhizal fungi (Glandorf et al. 1997). Moreover, resistance against one pathogen may result in enhanced susceptibility to another pathogen or insect. There is ample evidence of cross communication between the SA and JA/ET defense pathways, which can act both synergistically or antagonistically (Reymond and Farmer 1998; Rojo et al. 2003; Bostock 2005; Beckers and Spoel 2006; Koornneef and Pieterse 2008; Pieterse et al. 2009). For instance, Spoel et al. (2007) recently showed that SA-mediated defenses triggered in Arabidopsis upon infection with $P$. syringae rendered the infected tissue more susceptible to A. brassicicola. Pathway crosstalk is thought to be a mechanism for fine-tuning defense responses by prioritizing which defensive strategy to employ to cope with the different organisms that (simultaneously) interact with the plant. Koornneef et al. (2008) demonstrated that timing of elicitation of SA and JA signaling pathways is crucial for determining which defense pathway to prioritize, suggesting that there is a window of opportunity during which JA- and SA-regulated defense responses can have cross-effects on organisms other than the attacker. Therefore, laboratory studies that concentrate on single plant-attacker combinations may not take all ecological costs into account. The challenge lies in unraveling the costs of defense mechanisms in a multitrophic environment, such as appears in nature.

\section{Fitness Benefits of Priming Under Disease Pressure}

While the inducibility of defenses may save resources under enemy-free conditions compared to constitutive activation of defenses, it also causes a time slot between attack and the expression of inducible defenses in which the plant is vulnerable to the attacker. Priming may be a mechanism to ease the trade-off dilemma between costly defense activation and effective protection against harmful organisms (Goellner and Conrath 2008), since primed plants do not activate defenses directly upon induction treatment but activate their defenses faster and stronger when subsequently attacked by pathogens or insects (Conrath et al. 2002, 2006). 
Most studies on the costs and benefits of plant defense have concentrated on direct activation of defenses, rather than on priming. Moreover, putative benefits of defenses under disease pressure were often not taken into account (Walters and Boyle 2005). We recently demonstrated in Arabidopsis that priming induced by BABA has clear benefits under conditions of disease pressure (Van Hulten et al. 2006). In the absence of pathogens, priming had no or only marginal effect on the relative growth rate (RGR) and seed production of the plant, whereas there were large effects when defenses were directly activated. In the presence of pathogens, a clear fitness advantage was observed for primed plants over non-primed plants and also over plants in which defenses were activated already before pathogen challenge (Van Hulten et al. 2006). These results clearly indicate that under conditions of disease pressure, the benefits of priming outweigh the costs. In agreement with our study, Walters et al. (2009) recently demonstrated in barley (Hordeum vulgare) that priming induced by saccharin, a metabolite of the synthetic SAR-inducer probenazole, had no significant effect on plant growth rate and grain yield in the absence of pathogen infection. However, priming significantly increased plant fitness under high inoculum pressure by the hemibiotrophic fungus Rhynchosporium secalis. To take unforeseen ecological costs into account, putative fitness costs of saccharin treatment under natural conditions were also evaluated in a field study. Saccharin treatment increased grain yield slightly but not significantly compared to untreated controls, indicating that priming for enhanced defense responses induced by saccharin did not incur allocation costs in barley under field conditions (Walters et al. 2009).

The studies of Van Hulten et al. (2006) and Walters et al. (2009) are the only ones to date that describe the fitness costs and fitness benefits associated with priming of defense. In these studies priming had been induced either chemically or genetically by the edrl mutation, which affects a MPKKK (MPK kinase kinase) that is a negative regulator of SA-inducible defense responses in Arabidopsis (Frye and Innes 1998; Frye et al. 2001). No study has yet been designed to elucidate fitness effects of ecologically more relevant induction of priming, like that induced by beneficial micro-organisms. However, Raupach and Kloepper (1998) reported that in two field trials, conducted in separate years, seed treatment of cucumber with PGPR Baccilus spp. increased plant growth and reduced disease severity against different pathogens. In another field study, Bacillus pretreatment protected cucumber plants from cucumber beetles and the beetle-transmittable bacterial wilt disease (Zehnder et al. 2001). This was accompanied by significant yield increases. Also field-grown tomato plants were protected by Baccilus spp. against the cucumber mosaic virus and tomato mottle virus, which was associated with increased plant yield compared to untreated plants (Zehnder et al. 2001). An increase in yield was not observed during a similar field trial conducted in the consecutive cropping season, but viral titers were also not affected by the bacteria in this second year (Zehnder et al. 2001). These results demonstrate fitness benefits for plants that interact with PGPR. These interactions do not seem to incur costs on the plant. Although the priming phenomenon was not the emphasis of these studies, priming is often found to be the underlying mechanism of systemic plant protection by PGPR (Van Wees et al. 2008; Van der Ent et al. 2009a). 


\section{To What Extent are Plants in the Field Already Primed?}

Priming has predominantly been studied under tightly controlled growth conditions with optimum temperature, light intensity, humidity, and nutrient availability for plant growth. In natural environments the above mentioned parameters could be less favorable for the plant. Furthermore, in nature plants interact with many organisms, such as pathogens, herbivores, other plants, and beneficial microorganisms (Pieterse and Dicke 2007). All these parameters may exert an effect on the plant and consequently on the priming response. Conversely, under natural conditions the priming response may have different effects on plant fitness or the plant's ability to respond to stresses than under controlled conditions, because of the different environment of the plant. This way, effects of priming may become apparent that would not be detected under controlled greenhouse conditions. Studies on the fitness consequences of plants that exhibit a primed defense state in the field will be instrumental to better understand the ecological impact of priming of defense responses. In earlier studies priming-inducing agents have shown to protect plants in the field (Beckers and Conrath 2007; Goellner and Conrath 2008). However, in these studies, the primed state was not verified, which is crucial to impute any protective effect of the agents to a primed state because most chemical priming agents can also activate defenses directly when applied at higher doses (Kohler et al. 2002; Van Hulten et al. 2006). Therefore, from these field studies, it cannot be concluded that the induced protection is caused by priming because contribution of direct activation of defenses can not be excluded. Also in field studies with PGPR and PGPF that can induce resistance through priming of defenses, additional protective mechanisms can not be excluded because many of these beneficials are capable of exerting direct effects on pathogenic organisms through competition for nutrients or production of antibiotics.

Since priming can be induced by a plethora of organisms, whether beneficial or harmful, it is possible that plants in the field are already primed to some extent through their continual interaction with the biotic (and abiotic) environment. Walters (2009) recently suggested that in several published field studies, defenses had already been induced in plants to some extent prior to induction treatment. For example, treatment of field-grown wheat with BTH, a functional analog of SA, did not induce SAR-related genes, which may be due to the already high expression levels of these genes before treatment (Pasquer et al. 2005). However, Herman et al. (2007) reported that tomato plants in the field responded to treatment with ASM, a functional analog of SA, with significant induction of defense-related gene expression, despite their enhanced basal level of expression in the field compared to in the greenhouse. Moreover, a second treatment with ASM resulted in a significantly stronger expression response relative to non-pretreated plants. This latter finding implies that although plants may be already primed, this does not compromise their ability to express even higher levels of induced resistance upon subsequent induction.

Priming of defense responses is an inducible phenomenon, indicating that by default the plant is in a noninduced or nonprimed physiological state. It would be 
interesting to investigate whether plants that grow in their natural habitat, in which they coevolved with indigenous micro-organisms and are well adapted to the local environment, have naturally acquired the primed state. For this purpose, proper controls need to be included (e.g., mutant plants that are affected in priming only) and markers strictly correlated with priming should be assessed. These tools are not known at the moment.

\section{Outlook}

In recent years, knowledge on resistance induced by beneficial root-colonizing microbes has greatly expanded. There is ever-growing information available on microbes with resistance-inducing activity, plant species that are perceptive to resistance-inducing microbes, and pathogens/insects to which the induced resistance is effective. The picture is emerging that the plant defense signaling pathway that is triggered by ISR-inducing beneficials depends on responsiveness to the plant hormones JA and ET. ISR is not accompanied by massive changes in gene expression. Instead, ISR is established through priming the plant for enhanced defense responses upon encountering a pathogen or insect. Priming seems to be a cost-efficient defense mechanism. Hence, beneficial microbes-induced priming may be an ecologically relevant feature of plants.

Priming by benefical microbes may be a valuable tool for sustainable crop protection. For effective use of priming agents in agriculture, it is critical to investigate whether and to what extent the specific crops in the field may be already primed by their interacting environment and whether this could be further enhanced by application of priming agents. However, the fact that JA-dependent ISR and SA-dependent SAR can have additive effects (Van Wees et al. 2000) implies that different defense pathways can be primed simultaneously, leaving room for enhancement of naturally primed defenses. PGPR can present an attractive alternative to chemical pesticides for protection against pathogens and insects. A major advantage of PGPR is that once systemic resistance is induced, the natural defense mechanisms of the plant are operative for prolonged periods (Van Loon et al. 1998). However, complete disease control is rarely provided by resistance-inducing agents. Research aimed at determining the factors that influence the success rate of the PGPR is necessary for broad implementation of biocontrol agents that consistently provide acceptable levels of disease control in crop protection programs. Besides inducing of resistance PGPR can also directly control soil-borne pathogens, through competition of nutrients or production of antibiotics. Therefore, (a combination of) PGPR strains that can protect plants through different mechanisms are ideally suited to confer consistent, long-lasting protection of crops against various diseases and pests. Mixtures of PGPR strains have indeed been shown to enhance biological control in cucumber and radish against different pathogens compared to the effect of single treatments (Raupach and Kloepper 1998; De Boer et al. 2003). 


\section{References}

Agrawal AA, Strauss SY, Stout MJ (1999) Costs of induced responses and tolerance to herbivory in male and female fitness components of wild radish. Evolution 53:1093-1104

Ahn I-P, Lee S-W, Suh S-C (2007) Rhizobacteria-induced priming in Arabidopsis is dependent on ethylene, jasmonic acid, and NPR1. Mol Plant Microbe Interact 20:759-768

Bakker PAHM, Pieterse CMJ, Van Loon LC (2007) Induced systemic resistance by fluorescent Pseudomonas spp. Phytopathology 97:239-243

Baldwin IT (1998) Jasmonate-induced responses are costly but benefit plants under attack in native populations. Proc Natl Acad Sci USA 95:8113-8118

Barto EK, Cipollini D (2005) Testing the optimal defense theory and the growth-differentiation balance hypothesis in Arabidopsis thaliana. Oecologia 146:169-178

Beckers GJM, Spoel SH (2006) Fine-tuning plant defence signalling: salicylate versus jasmonate. Plant Biol 8:1-10

Beckers GJM, Conrath U (2007) Priming for stress resistance: from the lab to the field. Curr Opin Plant Biol 10:425-431

Beckers GJM, Jaskiewicz M, Liu Y, Underwood WR, He SY, Zhang S, Conrath U (2009) Mitogen-activated proteinkinases 3 and 6 are required for full priming of stress responses in Arabidopsis thaliana. Plant Cell 21:944-953

Berger S, Sinha AK, Roitsch T (2007) Plant physiology meets phytopathology: plant primary metabolism and plant-pathogen interactions. J Exp Bot 58:4019-4026

Bloemberg GV, Lugtenberg BJJ (2001) Molecular basis of plant growth promotion and biocontrol by rhizobacteria. Curr Opin Plant Biol 4:343-350

Bostock RM (2005) Signal crosstalk and induced resistance: straddling the line between cost and benefit. Annu Rev Phytopathol 43:545-580

Bowling SA, Guo A, Cao H, Gordon AS, Klessig DF, Dong X (1994) A mutation in Arabidopsis that leads to constitutive expression of systemic acquired resistance. Plant Cell 6:1845-1857

Bruce TJA, Matthes MC, Napier JA, Pickett JA (2007) Stressful "memories" of plants: evidence and possible mechanisms. Plant Sci 173:603-608

Cameron RK, Paiva NC, Lamb CJ, Dixon RA (1999) Accumulation of salicylic acid and $P R$ gene transcripts in relation to the systemic acquired resistance (SAR) response by Pseudomonas syringae pv. tomato in Arabidopsis. Physiol Mol Plant Pathol 55:121-130

Cao H, Bowling SA, Gordon AS, Dong X (1994) Characterization of an Arabidopsis mutant that is nonresponsive to inducers of systemic acquired resistance. Plant Cell 6:1583-1592

Cartieaux F, Contesto C, Gallou A, Desbrosses G, Kopka J, Taconnat L, Renou J-P, Touraine B (2008) Simultaneous interaction of Arabidopsis thaliana with Bradyrhizobium sp. strain ORS278 and Pseudomonas syringae pv. tomato DC3000 leads to complex transcriptome changes. Mol Plant Microbe Interact 21:244-259

Cipollini DF (2002) Does competition magnify the fitness costs of induced responses in Arabidopsis thaliana? A manipulative approach. Oecologia 131:514-520

Conrath U, Pieterse CMJ, Mauch-Mani B (2002) Priming in plant-pathogen interactions. Trends Plant Sci 7:210-216

Conrath U, Beckers GJM, Flors V, García-Agustín P, Jakab G, Mauch F, Newman M-A, Pieterse CMJ, Poinssot B, Pozo MJ, Pugin A, Schaffrath U, Ton J, Wendehenne W, Zimmerli L, Mauch-Mani B (2006) Priming: getting ready for battle. Mol Plant Microbe Interact 19:1062-1071

De Boer M, Bom P, Kindt F, Keurentjes JJB, Van der Sluis I, Van Loon LC, Bakker PAHM (2003) Control of Fusarium wilt of radish by combining Pseudomonas putida strains that have different disease-suppressive mechanisms. Phytopathology 93:626-632

De Bruijn I, De Kock MJD, Yang M, De Waard P, Van Beek TA, Raaijmakers JM (2007) Genome-based discovery, structure prediction and functional analysis of cyclic lipopeptide antibiotics in Pseudomonas species. Mol Microbiol 63:417-428 
De Meyer G, Bigirimana J, Elad Y, Höfte M (1998) Induced systemic resistance in Trichoderma harzianum T39 biocontrol of Botrytis cinerea. Eur J Plant Pathol 104:279-286

De Vos M, Van Zaanen W, Koornneef A, Korzelius JP, Dicke M, Van Loon LC, Pieterse CMJ (2006) Herbivore-induced resistance against microbial pathogens in Arabidopsis. Plant Physiol 142:352-363

De Vos M, Van Oosten VR, Van Poecke RMP, Van Pelt JA, Pozo MJ, Muelle MJ, Buchala AJ, Métraux JP, Van Loon LC, Dicke M, Pieterse CMJ (2005) Signal signature and transcriptome changes of Arabidopsis during pathogen and insect attack. Mol Plant Microbe Interact 18:923-937

Delaney TP, Friedrich L, Ryals JA (1995) Arabidopsis signal transduction mutant defective in chemically and biologically induced disease resistance. Proc Natl Acad Sci USA 92: 6602-6606

Dietrich R, Ploss K, Heil M (2004) Constitutive and induced resistance to pathogens in Arabidopsis thaliana depends on nitrogen supply. Plant Cell Environ 27:896-906

Dietrich R, Ploss K, Heil M (2005) Growth responses and fitness costs after induction of pathogen resistance depend on environmental conditions. Plant Cell Environ 28:211-222

Dong J, Chen C, Chen Z (2003) Expression profiles of the Arabidopsis WRKY gene superfamily during plant defense response. Plant Mol Biol 51:21-37

Durrant WE, Dong X (2004) Systemic acquired resistance. Annu Rev Phytopathol 42:185-209

Ellis C, Turner JG (2001) The Arabidopsis mutant cevl has constitutively active jasmonate and ethylene signal pathways and enhanced resistance to pathogens. Plant Cell 13:1025-1033

Engelberth J, Alborn HT, Schmelz EA, Tumlinson JH (2004) Airborne signals prime plants against insect herbivore attack. Proc Natl Acad Sci USA 101:1781-1785

Fan WH, Dong XN (2002) In vivo interaction between NPR1 and transcription factor TGA2 leads to salicylic acid-mediated gene activation in Arabidopsis. Plant Cell 14:1377-1389

Frye CA, Innes RW (1998) An Arabidopsis mutant with enhanced resistance to powdery mildew. Plant Cell 10:947-956

Frye CA, Tang DZ, Innes RW (2001) Negative regulation of defense responses in plants by a conserved MAPKK kinase. Proc Natl Acad Sci USA 98:373-378

Glandorf DCM, Bakker PAHM, Van Loon LC (1997) Influence of the production of antibacterial and antifungal proteins by transgenic plants on the saprophytic soil microflora. Acta Bot Neerl 46:85-104

Goellner K, Conrath U (2008) Priming: it's all the world to induced disease resistance. Eur J Plant Pathol 121:233-242

Harman GE, Howell CR, Viterbo A, Chet I, Lorito M (2004) Trichoderma species-opportunistic, avirulent plant symbionts. Nat Rev Microbiol 2:43-56

Harrison MJ (2005) Signaling in the arbuscular mycorrhizal symbiosis. Annu Rev Microbiol 59:19-42

Hase S, Van Pelt JA, Van Loon LC, Pieterse CMJ (2003) Colonization of Arabidopsis roots by Pseudomonas fluorescens primes the plant to produce higher levels of ethylene upon pathogen infection. Physiol Mol Plant Pathol 62:219-226

Heidel AJ, Clarke JD, Antonovics J, Dong X (2004) Fitness costs of mutations affecting the systemic acquired resistance pathway in Arabidopsis thaliana. Genetics 168:2197-2206

Heil M (2002) Ecological costs of induced resistance. Curr Opin Plant Biol 5:345-350

Heil M, Baldwin IT (2002) Fitness costs of induced resistance: emerging experimental support for a slippery concept. Trends Plant Sci 7:61-67

Heil M, Hilper A, Kaiser W, Linsenmair KE (2000) Reduced growth and seed set following chemical induction of pathogen defence: does systemic acquired resistance (SAR) incur allocation costs? J Ecol 88:645-654

Herman MAB, Restrepo S, Smart CD (2007) Defense gene expression patterns of three SARinduced tomato cultivars in the field. Physiol Mol Plant Pathol 71:192-200

Jones JDG, Dangl JL (2006) The plant immune system. Nature 444:323-329 
Jung HW, Tschaplinski TJ, Wang L, Glazebrook J, Greenberg JT (2009) Priming in systemic plant immunity. Science 324:89-91

Kagaya Y, Hobo T, Murata M, Ban A, Hattori T (2002) Abscisic acid-induced transcription is mediated by phosphorylation of an abscisic acid response element binding factor, TRAB1. Plant Cell 14:3177-3189

Kloepper JW, Ryu C-M, Zhang SA (2004) Induced systemic resistance and promotion of plant growth by Bacillus spp. Phytopathology 94:1259-1266

Knoester M, Pieterse CMJ, Bol JF, Van Loon LC (1999) Systemic resistance in Arabidopsis induced by rhizobacteria requires ethylene-dependent signaling at the site of application. Mol Plant Microbe Interact 12:720-727

Kohler A, Schwindling S, Conrath U (2002) Benzothiadiazole-induced priming for potentiated responses to pathogen infection, wounding, and infiltration of water into leaves requires the NPR1/NIM1 gene in Arabidopsis. Plant Physiol 128:1046-1056

Koornneef A, Pieterse CMJ (2008) Cross talk in defense signaling. Plant Physiol 146:839-844

Koornneef A, Leon-Reyes A, Ritsema T, Verhage A, Den Otter FC, Van Loon LC, Pieterse CMJ (2008) Kinetics of salicylate-mediated suppression of jasmonate signaling reveal a role for redox modulation. Plant Physiol 147:1358-1368

Lawton K, Weymann K, Friedrich L, Vernooij B, Uknes S, Ryals J (1995) Systemic acquired resistance in Arabidopsis requires salicylic acid but not ethylene. Mol Plant Microbe Interact 8:863-870

Leeman M, Van Pelt JA, Den Ouden FM, Heinsbroek M, Bakker PAHM, Schippers B (1995) Induction of systemic resistance against fusarium wilt of radish by lipopolysaccharides of Pseudomonas fluorescens. Phytopathology 85:1021-1027

Leon-Reyes A, Spoel SH, De Lange ES, Abe H, Kobayashi M, Tsuda S, Millenaar FF, Welschen RAM, Ritsema T, Pieterse CMJ (2009) Ethylene modulates the role of NONEXPRESSOR OF PATHOGENESIS-RELATED GENES1 in cross talk between salicylate and jasmonate signaling. Plant Physiol 149:1797-1809

Liu J, Maldonado-Mendoza I, Lopez-Meyer M, Cheung F, Town CD, Harrison MJ (2007) Arbuscular mycorrhizal symbiosis is accompanied by local and systemic alterations in gene expression and an increase in disease resistance in the shoots. Plant J 50:529-544

Lorenzo O, Solano R (2005) Molecular players regulating the jasmonate signalling network. Curr Opin Plant Biol 8:532-540

Lorenzo O, Chico JM, Sanchez-Serrano JJ, Solano R (2004) JASMONATE-INSENSITIVE1 encodes a MYC transcription factor essential to discriminate between different jasmonateregulated defense responses in Arabidopsis. Plant Cell 16:1938-1950

Maleck K, Levine A, Eulgem T, Morgan A, Schmid J, Lawton KA, Dangl JL, Dietrich RA (2000) The transcriptome of Arabidopsis thaliana during systemic acquired resistance. Nat Genet 26:403-410

Mosher RA, Durrant WE, Wang D, Song J, Dong X (2006) A comprehensive structure-function analysis of Arabidopsis SNI1 defines essential regions and transcriptional repressor activity. Plant Cell 18:1750-1765

Mou Z, Fan W, Dong X (2003) Inducers of plant systemic acquired resistance regulate NPR1 function through redox changes. Cell 113:935-944

Nürnberger T, Brunner F, Kemmerling B, Piater L (2004) Innate immunity in plants and animals: striking similarities and obvious differences. Immunol Rev 198:249-266

Osbourn AE (1996) Preformed antimicrobial compounds and plant defense against fungal attack. Plant Cell 8:1821-1831

Pasquer F, Isidore E, Zarn J, Keller B (2005) Specific patterns of changes in wheat gene expression after treatment with three antifungal compounds. Plant Mol Biol 57:693-707

Pieterse CMJ, Dicke M (2007) Plant interactions with microbes and insects: from molecular mechanisms to ecology. Trends Plant Sci 12:564-569

Pieterse CMJ, Leon-Reyes A, Van der Ent S, Van Wees SCM (2009) Networking by smallmolecule hormones in plant immunity. Nat Chem Biol 5:308-316 
Pieterse CMJ, Van Wees SCM, Hoffland E, Van Pelt JA, Van Loon LC (1996) Systemic resistance in Arabidopsis induced by biocontrol bacteria is independent of salicylic acid accumulation and pathogenesis-related gene expression. Plant Cell 8:1225-1237

Pieterse CMJ, Van Wees SCM, Van Pelt JA, Knoester M, Laan R, Gerrits H, Weisbeek PJ, Van Loon LC (1998) A novel signaling pathway controlling induced systemic resistance in Arabidopsis. Plant Cell 10:1571-1580

Pozo MJ, Azcón-Aguilar C (2007) Unraveling mycorrhiza-induced resistance. Curr Opin Plant Biol 10:393-398

Pozo MJ, Van der Ent S, Van Loon LC, Pieterse CMJ (2008) Transcription factor MYC2 is involved in priming for enhanced defense during rhizobacteria-induced systemic resistance in Arabidopsis thaliana. New Phytol 180:511-523

Pré M, Atallah M, Champion A, De Vos M, Pieterse CMJ, Memelink J (2008) The AP2/ERF domain transcription factor ORA59 integrates jasmonic acid and ethylene signals in plant defense. Plant Physiol 147:1347-1357

Raupach GS, Kloepper JW (1998) Mixtures of plant growth-promoting rhizobacteria enhance biological control of multiple cucumber pathogens. Phytopathology 88:1158-1164

Reymond P, Farmer EE (1998) Jasmonate and salicylate as global signals for defense gene expression. Curr Opin Plant Biol 1:404-411

Rojo E, Solano R, Sanchez-Serrano JJ (2003) Interactions between signaling compounds involved in plant defense. J Plant Growth Regul 22:82-98

Roman G, Lubarsky B, Kieber JJ, Rothenberg M, Ecker JR (1995) Genetic analysis of ethylene signal transduction in Arabidopsis thaliana: five novel mutant loci integrated into a stress response pathway. Genetics 139:1393-1409

Schwessinger B, Zipfel C (2008) News from the frontline: recent insights into PAMP-triggered immunity in plants. Curr Opin Plant Biol 11:389-395

Segarra G, Van der Ent S, Trillas I, Pieterse CMJ (2009) MYB72, a node of convergence in induced systemic resistance triggered by a fungal and a bacterial beneficial microbe. Plant Biol 11:90-96

Shah J, Tsui F, Klessig DF (1997) Characterization of a salicylic acid-insensitive mutant (sail) of Arabidopsis thaliana, identified in a selective screen utilizing the SA-inducible expression of the tms2 gene. Mol Plant Microbe Interact 10:69-78

Shoresh M, Yedidia I, Chet I (2005) Involvement of jasmonic acid/ethylene signaling pathway in the systemic resistance induced in cucumber by Trichoderma asperellum T203. Phytopathology 95:76-84

Spaink HP (2000) Root nodulation and infection factors produced by rhizobial bacteria. Annu Rev Microbiol 54:257-288

Spoel SH, Johnson JS, Dong X (2007) Regulation of tradeoffs between plant defenses against pathogens with different lifestyles. Proc Natl Acad Sci USA 104:18842-18847

Spoel SH, Koornneef A, Claessens SMC, Korzelius JP, Van Pelt JA, Mueller MJ, Buchala AJ, Métraux J-P, Brown R, Kazan K, Van Loon LC, Dong X, Pieterse CMJ (2003) NPR1 modulates cross-talk between salicylate- and jasmonate-dependent defense pathways through a novel function in the cytosol. Plant Cell 15:760-770

Stein E, Molitor A, Kogel K-H, Waller F (2008) Systemic resistance in Arabidopsis conferred by the mycorrhizal fungus Piriformospora indica requires jasmonic acid signaling and the cytoplasmic function of NPR1. Plant Cell Physiol 49:1747-1751

Ton J, Van Pelt JA, Van Loon LC, Pieterse CMJ (2002) Differential effectiveness of salicylatedependent and jasmonate/ethylene-dependent induced resistance in Arabidopsis. Mol Plant Microbe Interact 15:27-34

Ton J, D'Alessandro M, Jourdie V, Jakab G, Karlen D, Held M, Mauch-Mani B, Turlings TCJ (2007) Priming by airborne signals boosts direct and indirect resistance in maize. Plant J 49:16-26

Van Dam NM, Baldwin IT (2001) Competition mediates costs of jasmonate-induced defences, nitrogen acquisition and transgenerational plasticity in Nicotiana attenuata. Funct Ecol $15: 406-415$ 
Van der Ent S, Van Wees SCM, Pieterse CMJ (2009a) Jasmonate signals in plant interactions with beneficial microbes. Phytochemistry 70:1581-1588

Van der Ent S, Van Hulten MHA, Pozo MJ, Czechowski T, Udvardi MK, Pieterse CMJ, Ton J (2009b) Priming of plant innate immunity by rhizobacteria and beta-aminobutyric acid: differences and similarities in regulation. New Phytol 183:419-431

Van der Ent S, Verhagen BWM, Van Doorn R, Bakker D, Verlaan MG, Pel MJC, Joosten RG, Proveniers MCG, Van Loon LC, Ton J, Pieterse CMJ (2008) MYB72 is required in early signaling steps of rhizobacteria-induced systemic resistance in Arabidopsis. Plant Physiol 146:1293-1304

Van Hulten M, Pelser M, Van Loon LC, Pieterse CMJ, Ton J (2006) Costs and benefits of priming for defense in Arabidopsis. Proc Natl Acad Sci USA 103:5602-5607

Van Loon LC (1997) Induced resistance and the role of pathogenesis-related proteins. Eur J Plant Pathol 103:753-765

Van Loon LC (2000) Systemic induced resistance. In: Slusarenko AJ, Fraser RSS, Van Loon LC (eds) Mechanisms of resistance to plant diseases. Kluwer, Dordrecht, pp 521-574

Van Loon LC, Van Strien EA (1999) The families of pathogenesis-related proteins, their activities, and comparative analysis of PR-1 type proteins. Physiol Mol Plant Pathol 55:85-97

Van Loon LC, Bakker PAHM (2005) Induced systemic resistance as a mechanism of disease suppression by rhizobacteria. In: Siddiqui ZA (ed) PGPR: biocontrol and biofertilization. Springer, Dordrecht, pp 39-66

Van Loon LC, Bakker PAHM (2006) Root-associated bacteria inducing systemic resistance. In: Gnanamanickam SS (ed) Plant-associated bacteria. Springer, Dordrecht, pp 269-316

Van Loon LC, Bakker PAHM, Pieterse CMJ (1998) Systemic resistance induced by rhizosphere bacteria. Annu Rev Phytopathol 36:453-483

Van Loon LC, Rep M, Pieterse CMJ (2006) Significance of inducible defense-related proteins in infected plants. Annu Rev Phytopathol 44:135-162

Van Oosten VR, Bodenhausen N, Reymond P, Van Pelt JA, Van Loon LC, Dicke M, Pieterse CMJ (2008) Differential effectiveness of microbially induced resistance against herbivorous insects in Arabidopsis. Mol Plant Microbe Interact 21:919-930

Van Peer R, Schippers B (1992) Lipopolysaccharides of plant-growth promoting Pseudomonas sp. strain WCS417r induce resistance in carnation to fusarium wilt. Neth J Plant Pathol 98:129-139

Van Peer R, Niemann GJ, Schippers B (1991) Induced resistance and phytoalexin accumulation in biological control of fusarium wilt of carnation by Pseudomonas sp. strain WCS417r. Phytopathology 81:728-734

Van Wees SCM, Van der Ent S, Pieterse CMJ (2008) Plant immune responses triggered by beneficial microbes. Curr Opin Plant Biol 11:443-448

Van Wees SCM, Luijendijk M, Smoorenburg I, Van Loon LC, Pieterse CMJ (1999) Rhizobacteria-mediated induced systemic resistance (ISR) in Arabidopsis is not associated with a direct effect on expression of known defense-related genes but stimulates the expression of the jasmonate-inducible gene Atvsp upon challenge. Plant Mol Biol 41:537-549

Van Wees SCM, De Swart EAM, Van Pelt JA, Van Loon LC, Pieterse CMJ (2000) Enhancement of induced disease resistance by simultaneous activation of salicylate- and jasmonate-dependent defense pathways in Arabidopsis thaliana. Proc Natl Acad Sci USA 97:8711-8716

Van Wees SCM, Pieterse CMJ, Trijssenaar A, Van't Westende YAM, Hartog F, Van Loon LC (1997) Differential induction of systemic resistance in Arabidopsis by biocontrol bacteria. Mol Plant Microbe Interact 10:716-724

Verhagen BWM, Glazebrook J, Zhu T, Chang H-S, Van Loon LC, Pieterse CMJ (2004) The transcriptome of rhizobacteria-induced systemic resistance in Arabidopsis. Mol Plant Microbe Interact 17:895-908

Vinale F, Sivasithamparam K, Ghisalberti EL, Marra R, Woo SL, Lorito M (2008) Trichodermaplant-pathogen interactions. Soil Biol Biochem 40:1-10 
Waller F, Achatz B, Baltruschat H, Fodor J, Becker K, Fischer M, Heier T, Huckelhoven R, Neumann C, von Wettstein D, Franken P, Kogel K-H (2005) The endophytic fungus Piriformospora indica reprograms barley to salt-stress tolerance, disease resistance, and higher yield. Proc Natl Acad Sci USA 102:13386-13391

Walters D, Heil M (2007) Costs and trade-offs associated with induced resistance. Physiol Mol Plant Pathol 71:3-17

Walters DR (2009) Are plants in the field already induced? Implications for practical disease control. Crop Protect 28:459-465

Walters DR, Boyle C (2005) Induced resistance and allocation costs: what is the impact of pathogen challenge? Physiol Mol Plant Pathol 66:40-44

Walters DR, Paterson L, Walsh DJ, Havis ND (2009) Priming for plant defense in barley provides benefits only under high disease pressure. Physiol Mol Plant Pathol 73:95-100

Wang D, Amornsiripanitch N, Dong X (2006) A genomic approach to identify regulatory nodes in the transcriptional network of systemic acquired resistance in plants. PLoS Pathog 2:1042-1050

Weller DM, Raaijmakers JM, McSpadden Gardener BB, Thomashow LS (2002) Microbial populations responsible for specific soil suppressiveness to pathogens. Annu Rev Phytopathol 40:309-348

Zehnder GW, Murphy JF, Sikora EJ, Kloepper JW (2001) Application of rhizobacteria for induced resistance. Eur J Plant Pathol 107:39-50

Zeyen RJ, Carver TLW, Lyngkjær MF (2002) The formation and role of papillae. Carver APS, St Paul, Minnesota

Zhang H, Xie X, Kim M-S, Kornyeyev DA, Holaday S, Paré PW (2008) Soil bacteria augment Arabidopsis photosynthesis by decreasing glucose sensing and abscisic acid levels in planta. Plant J 56:264-273

Zimmerli L, Métraux J-P, Mauch-Mani B (2001) b-Aminobutyric acid-induced protection of Arabidopsis against the necrotrophic fungus Botrytis cinerea. Plant Physiol 126:517-523

Zimmerli L, Jakab G, Métraux J-P, Mauch-Mani B (2000) Potentiation of pathogen-specific defense mechanisms in Arabidopsis by b-aminobutyric acid. Proc Natl Acad Sci USA 97:12920-12925 